\title{
Women's Satisfaction and Its Associated Factors with Antenatal Care Services at Public Health Facilities: A Cross-Sectional Study
}

This article was published in the following Dove Press journal: International Journal of Women's Health

\author{
Mequannent Melaku Ayalew' \\ Gebeyehu Tsega Nebeb' \\ Mekonnen Melikie Bizuneh' \\ Asrat Hailu Dagne (D) ${ }^{2}$ \\ 'School of Public Health, Bahir Dar \\ University, Bahir Dar, Amhara Region, \\ Ethiopia; ${ }^{2}$ Department of Midwifery, \\ Debre Tabor University, Debre Tabor, \\ Amhara Region, Ethiopia
}

Background: Regular monitoring and evaluation improves the quality of health services. Client satisfaction is an indicator of the quality of a health service. Poor maternal satisfaction with antenatal care services has negative outcomes. Currently, women's satisfaction with antenatal care services is below standard in low-income countries such as Ethiopia. Therefore, this study aimed to assess women's satisfaction and its associated factors with antenatal care services.

Methods: A facility-based cross-sectional study was conducted from September 23 to October 23, 2019. A total of 405 women were involved in the study. A systematic random sampling technique was used. The data were coded manually and checked visually for completeness. The data were entered using Epi Info version 7 and exported to SPSS version 20 for analysis. Descriptive statistic was computed. Thechi-squared test was performed and factors associated with women's satisfaction with antenatal care services were selected for multiple logistic regression at a probability value ( $p$-value) of $<0.2$ in the chi-square $\mathrm{d}$ analysis. Statistically significant associated factors were identified at a $p$-value of $\leq 0.05$, and with adjusted odds ratios and 95\% confidence intervals.

Results: Among 405 participants, 53.8\% (95\% CI=48.7-59\%) of women were satisfied with the antenatal care services. Age of mothers $(\mathrm{AOR}=6.04,95 \% \mathrm{CI}=2.3-15.9)$, advice on danger signs in pregnancy $(\mathrm{AOR}=4.53,95 \% \mathrm{CI}=2.7-7.52)$, previous antenatal care visits $(\mathrm{AOR}=3.8$, 95\% $\mathrm{CI}=2.0-7.52)$, respectful maternity care $(\mathrm{AOR}=8.2,95 \% \mathrm{CI}=3.3-20.4)$, and planned pregnancy $(\mathrm{AOR}=2.8,95 \% \mathrm{CI}=1.6-4.8)$ were statistically significantly associated with women's satisfaction with antenatal care services.

Conclusion: About half of the participants were satisfied with the antenatal care services. Age of participants, respectful maternity care, advice on danger signs in pregnancy, previous antenatal care visits, and planned pregnancy were found to be predictors of women's satisfaction with antenatal care services.

Keywords: satisfaction, respectful maternity care, antenatal care
Correspondence: Asrat Hailu Dagne Tel +25196372499 I

Email I22IAsrat@gmail.com

\section{Plain Language Summary}

Antenatal care is a vital time to promote healthy behavior. Client satisfaction is one of the indicators of the quality of health services. Poor maternal satisfaction with antenatal care services has negative outcomes. Currently, women's satisfaction with antenatal care services in low-income countries is below standard. Therefore, this study aimed to assess women's satisfaction and its associated factors with antenatal care services.

Women's satisfaction with antenatal care services was studied. This study found that women's satisfaction with antenatal care services is typically improved through increasing 
advice on danger signs in pregnancy, respectful maternity care, planned pregnancy, and number of antenatal care visits. These findings will serve as a baseline for measuring and monitoring change in women's satisfaction with antenatal care services. Thus, health intervention on participants whose age is $>35$ years, respectful maternity care, advice of danger signs in pregnancy, planned pregnancy and antenatal care visit is mandatory to improve women's satisfaction with antenatal care services.

\section{Introduction}

Different models can be used for the implementation, assessment, and measurement of quality of care. The most common model is Donabedian's logic model, which has structure, process, and outcome parts. Donabedian defined satisfaction as the extent of the client's experience compared with expectations. He considered client satisfaction to be one of the important indicators of the quality of health-care services. ${ }^{1}$ Patient satisfaction is the patient's judgement on the quality of care in all aspects particulartly considering the interpersonal process and it is the level of difference between patient expectations of ideal care and his/her perception of real care. Moreover, it is an important indicator of quality of healthcare. ${ }^{2}$ Owing to the variation in quality of health-care service delivery, patient satisfaction is different from facility to facility. ${ }^{3}$

Dissatisfaction of women with antenatal care (ANC) services has different consequences, such as poor adherence to treatment, poor participation in their own health care, breaking the continuum of care, and increasing maternal morbidity and mortality. ${ }^{4,5}$ The maternal mortality ratio (MMR) has been reduced through different activities, such as training health workers, recruiting midwives at each health facility, monitoring activities at different level of the health system, and providing exempted ANC services. Moreover, women's satisfaction with ANC services ensures a continuum of maternal care and enhances the improvement of quality ANC services. ${ }^{6}$

$\mathrm{ANC}$ is a vital time to promote healthy behavior and for women to acquire the skills of bearing a child. Adequate and quality ANC during pregnancy ensures continuity of care. Women's satisfaction is crucial for this continuity of ANC. ${ }^{7}$ ANC services are delivered all around the globe to reduce pregnancy-related morbidity and mortality. The MMR is especially high in sub-Saharan Africa, including Ethiopia. There is regional variation in maternal mortality, ranging from 12 to 546 deaths per 100,000 live births in high-income countries and low-income countries, respectively. ${ }^{8}$ Maternal mortality is 412 deaths per 100,000 live births in Ethiopia, which is far higher than the global target of reducing maternal mortality to less than 70 per 100,000 live births by $2030 .^{9}$

Maternal satisfaction is affected by different dimensions such as structure (physical environment, availability of adequate human resources, medicines, and supplies), process (interpersonal behavior, privacy, promptness, cognitive care, perceived provider competency, and emotional support), and outcome (health status of the mother and newborn). ${ }^{10}$ The magnitude of women's satisfaction with ANC services varies from country to country. ${ }^{10}$ Around $31 \%$ of women were dissatisfied with ANC services in America ${ }^{11}$ and about $62 \%$ of women were dissatisfied with ANC services in Nepal. ${ }^{12}$ The magnitude of women's satisfaction with ANC services ranges from $80 \%$ to $90 \%$ in Asian countries. ${ }^{13-15}$ Studies in Africa showed that $42.94 \%$ of women were satisfied with ANC services. ${ }^{16-18}$

Women's satisfaction with ANC services has varied in different studies. Factors associated with women's satisfaction with ANC services are different according to the study setting. Some factors such as respectful maternity care, advice on danger signs in pregnancy and age of participants haven't been identified in Ethiopia. Women's satisfaction with ANC services indicates steps in improving the quality of health care. Highquality health care is safe for patients. This study provided an opportunity to identify the factors that affect women's satisfaction with ANC services based on the study setting. The findings will also serve as a baseline for measuring and monitoring changes in women's satisfaction of ANC services. Therefore, this study aimed to assess women's satisfaction with ANC services and its associated factors among pregnant women using ANC services.

\section{Materials and Methods}

\section{Study Design and Setting}

A cross-sectional study was conducted from September 23 to October 23, 2019, among pregnant women who had used the ANC services at Debre Tabor public health facilities. Debre Tabor is the capital of South Gondar Administrative Zone of the Amhara Region, Ethiopia. Pregnant mothers who had accessed ANC services in Debre Tabor General Hospital, Debre Tabor Health Center, Ginbot 20 Health Center, and Hidar 11 Health Center were considered. Debre Tabor General Hospital serves approximately 2.3 million people and each of the three health centers serves more than 
25,000 people. Two obstetricians/gynecologists, four masters in emergency surgery and obstetrics, and 19 midwives provided ANC services at Debre Tabor General Hospital. Moreover, four midwives and two nurses provided ANC services at each of the health centers.

\section{Participants}

All mothers who had ANC follow-up at the included health facilities made up the study population. The sample size was calculated using a single population proportion formula. The required sample size for this study was determined using the following assumptions: desired precision $(d)=5 \%$, confidence level $=95 \%(Z \alpha / 2=1.96)$, and $60.4 \%$ of women's satisfaction with ANC services in public health facilities of Jimma Town. ${ }^{19}$ Hence, the calculated sample size, considering a $10 \%$ non-response rate, was 405. Based on a six-month review report of 2019, a total of 2338 mothers who had used ANC services were reported in four public health facilities, comprising 246 from Debre Tabor Health Center, 224 from Hidar 11 Health Center, 104 from Ginbot 20 Health Center, and 1764 from Debre Tabor General Hospital. A systematic random sampling technique was used to select study participants.

The first respondent was taken randomly from the first six mothers who had received ANC services on the starting day of data collection. After the individual sampling unit had been selected by a systematic random sampling technique, every sixth woman was selected as a participant until the required sample size was achieved in the included public health facilities.

\section{Data Collection Instruments and Procedures}

Questionnaires were developed following a detailed examination of the literature. Valid and reliable instruments were considered. The questionnaires had subsections on women's satisfaction with ANC services, sociodemographic variables, health serviceand obstetricsrelated characteristics. Questionnaires were prepared first in English then translated by a language expert into Amharic, which is the colloquial language of the respondents, for ease of understanding of the respondents. Questionnaires were also retranslated back to English for consistency. Women's satisfaction with ANC services was the outcome variable, and 14 questionnaires were used to determine the outcome variable. Each questionnaire was answered as strongly agree, agree, neither agree nor disagree, disagree, and strongly disagree (on a five-point Likert scale). Questionnaires relating to women's satisfaction with ANC services comprised 14 items with a total scale score ranging from 14 to 70 . First, the mean score of each participant was calculated. Second, the total mean score of all participants was calculated. Participants who had greater than or equal to the total mean score were considered to be satisfied. Participants who had below the total mean score were considered to be dissatisfied with the ANC services. ${ }^{5}$

\section{Operational Definitions}

Women's satisfaction with ANC services means that the women scored greater than or equal to the overall mean satisfaction score, from the total women's satisfaction with ANC services-related questionnaires. ${ }^{5}$

Respectful maternity care means that the participants had no reports of disrespect and abuse during ANC services, from the total 17 disrespectful maternity care-related questions. $^{20}$

Disrespectful maternal care means that the participants reported one or more instance of disrespect and abuse during ANC services, from the total 17 disrespectful maternity care-related questions. ${ }^{20}$

\section{Data Collection}

Data were collected via face-to-face interviews using semi-structured questionnaires. Data collectors were selected based on the criterion of previous exposure to data collection. Four data collectors and one supervisor were involved in data collection. They were trained to be familiar with the objective and the methodology of the research. The pretest was conducted among 21 (5\%) of the participants at Addis Zemen Primary Hospital before the actual data collection day. The data collection started with greetings and good communication. Data quality was checked at the time of interview during data collection. To ensure consistency, the same two questions were asked at the beginning and the end of data collection. A reliability test was checked by Cronbach's alpha and the result was 0.8. This indicates that the items were internally consistent. The supervisor and investigators closely supervised the performance of data collectors on a daily basis during the actual data collection. The data were checked again after data collection for completeness and internal validity. 


\section{Data Processing and Analysis}

The investigators and supervisor checked the data manually for completeness. Data were entered into Epi Info version 7 then exported to SPSS version 20 for statistical analysis. The data were cleaned for errors prior to data analysis. Cleaning for inconsistencies and missing values was checked visually using frequencies. After cleaning, descriptive statistics (frequencies, mean and standard deviation) analysis was performed. Cronbach's alpha was used to measure reliability, mean, standard deviation, and interitem correlation of the outcome variable.

The chi-squared test was performed and factors associated with postpartum hemorrhage were selected for multiple logistic regression at a probability value ( $p$-value) of less than 0.2 in the chi-squared analysis to control for potential confounding variables. Statistically significant associated factors were identified based on a $p$-value less than or equal to 0.05 and adjusted odds ratio (AOR) with $95 \%$ confidence interval (CI).

\section{Ethics Approval and Informed Consent}

Ethical clearance was obtained from the Institutional Review Board of Bahir Dar University, College of Medicine and Health Science. A formal letter of cooperation was written to Debre Tabor town health facilities. We stated that the participants had the right to refuse to participate in the study. They had also the right to quit the study at any stage without any restrictions. We provided information on the purpose, procedures, advantages, and disadvantages of the study, and informed written consent was obtained from each study participant. However, written informed consent was not obtained from the parent or guardian of any participants because all participants were at least 18 years old.

\section{Results}

\section{Socio-Demographic Characteristics}

Among the total 405 samples, the response rate of the participants was $100 \%$. Descriptive statistics of pregnant women were analyzed. The minimum age of the participants was 18 years and the mean age of participants was 27.32 ( $\mathrm{SD} \pm 3.942$ ) years. About half of the participants were in the age group between 25 and 29 years. The majority of the women were married and most of the respondents were of the Amhara ethnic group (Table 1).
Table I Socio-Demographic Characteristics of Pregnant Mothers Attending Antenatal Care at Public Health Facilities, Ethiopia, 2019

\begin{tabular}{|c|c|c|}
\hline Variables & $\begin{array}{l}\text { Frequency } \\
(n=405)\end{array}$ & $\begin{array}{l}\text { Percent } \\
\text { (\%) }\end{array}$ \\
\hline \multicolumn{3}{|l|}{ Marital status } \\
\hline Married & 392 & 96.8 \\
\hline Single & 13 & 3.2 \\
\hline \multicolumn{3}{|l|}{ Woman's educational status } \\
\hline Informal education & 58 & 14.3 \\
\hline Primary education (Ist-8th grade) & 89 & 22 \\
\hline Secondary education (9th-12th grade) & 85 & 21 \\
\hline Tertiary education (above 12th grade) & 173 & 42.7 \\
\hline \multicolumn{3}{|l|}{ Maternal age (years) } \\
\hline $18-24$ & 88 & 21.7 \\
\hline $25-29$ & 210 & 51.8 \\
\hline $30-34$ & 76 & 18.8 \\
\hline$\geq 35$ & 31 & 7.7 \\
\hline \multicolumn{3}{|l|}{ Occupation } \\
\hline Housewife and farmer & 215 & 53.1 \\
\hline Employee & 117 & 28.9 \\
\hline Merchant & 73 & 18 \\
\hline \multicolumn{3}{|l|}{ Religion } \\
\hline Orthodox & 396 & 97.8 \\
\hline Others & 9 & 2.2 \\
\hline \multicolumn{3}{|l|}{ Ethnicity } \\
\hline Amhara & 405 & 100 \\
\hline \multicolumn{3}{|l|}{ Family income per month (US dollars) } \\
\hline$<34$ & 45 & 21.7 \\
\hline $34-99$ & 141 & 51.8 \\
\hline $100-166$ & 106 & 18.8 \\
\hline$>166$ & 113 & 7.7 \\
\hline
\end{tabular}

Note: Others (religion): Muslim and Protestant.

\section{Obstetric-Related Characteristics}

Of the total participants, $185(45.7 \%)$ had no living children. Among the total samples, 152 participants (37.5\%) had one child, 42 (10.4\%) had two children, and $26(6.4 \%)$ had more than two children. The frequencies and percentages of other obstetric-related characteristics are presented in Table 2.

\section{Health Service-Related Characteristics}

All participants received laboratory and medication services without paying. Priority was given for $18 \%$ (73) of the participants to obtain laboratory services, whereas $82 \%$ (332) of women did not receive priority laboratory 
Table 2 Obstetric-Related Characteristics of Pregnant Women Attending Antenatal Care at Public Health Facilities, Ethiopia, 2019

\begin{tabular}{|c|c|c|}
\hline Variables & Frequency $(n=405)$ & Percent (\%) \\
\hline \multicolumn{3}{|l|}{ Parity } \\
\hline 0 & 155 & 38.3 \\
\hline 1 or 2 & 187 & 46.2 \\
\hline$>2$ & 63 & 15.5 \\
\hline \multicolumn{3}{|l|}{ Number of pregnancies } \\
\hline 1 & 102 & 25.2 \\
\hline 2 & 169 & 41.7 \\
\hline$>2$ & 134 & 33.1 \\
\hline \multicolumn{3}{|l|}{ Had previous history of ANC } \\
\hline Yes & 313 & 77.3 \\
\hline No & 92 & 22.7 \\
\hline \multicolumn{3}{|l|}{ Type of pregnancy } \\
\hline Unplanned & 228 & 56.3 \\
\hline Planned & 177 & 43.7 \\
\hline \multicolumn{3}{|l|}{ Number of previous ANC visits } \\
\hline 0 or 1 & 166 & 41 \\
\hline 2 & 80 & 19.7 \\
\hline 3 & 96 & 23.7 \\
\hline$\geq 4$ & 63 & 15.6 \\
\hline \multicolumn{3}{|l|}{ Had previous history of abortion } \\
\hline Yes & 117 & 28.9 \\
\hline No & 288 & 71.1 \\
\hline \multicolumn{3}{|l|}{ Had previous history of stillbirth } \\
\hline Yes & 59 & 14.6 \\
\hline No & 346 & 85.4 \\
\hline
\end{tabular}

Abbreviation: ANC, antenatal care.

services. The frequencies and percentages of other health service-related variable are presented in Table 3.

\section{Factors Associated with Women's}

\section{Satisfaction with Antenatal Care Services}

Among the 405 participants, 53.8\% (95\% $\mathrm{CI}=48.7-59 \%)$ of women were satisfied with the ANC services. Factors found to be associated ( $p$-value $\leq 0.2$ with 95\% CI) with women's satisfaction with ANC services using bivariate analysis were age, educational status, the time taken to reach the nearby health facility, number of pregnancies, planned pregnancy, waiting time to obtain the ANC service, previous ANC visits, previous history of abortion, previous history of stillbirth, advice on danger signs in pregnancy, and respectful maternity care.

The analysis indicated that mothers being aged 18-24 years $(\mathrm{AOR}=4.45, \mathrm{CI}=1.5-12.9), 24-29$ years $(\mathrm{AOR}=6.04$,
Table 3 Health Service-Related Characteristics of Pregnant Women Attending Antenatal Care at Public Health Facilities, Ethiopia, 2019

\begin{tabular}{|c|c|c|}
\hline Variables & $\begin{array}{l}\text { Frequency } \\
(n=405)\end{array}$ & $\begin{array}{l}\text { Percent } \\
\text { (\%) }\end{array}$ \\
\hline \multicolumn{3}{|l|}{ Level of health facility } \\
\hline Hospital & 305 & 75.3 \\
\hline Health center & 100 & 24.7 \\
\hline \multicolumn{3}{|l|}{$\begin{array}{l}\text { Time taken to reach nearby health } \\
\text { facility }\end{array}$} \\
\hline$\leq \mathrm{lh}$ & 328 & 81 \\
\hline$>I h$ & 77 & 19 \\
\hline \multicolumn{3}{|l|}{$\begin{array}{l}\text { Clean and adequate waiting area for } \\
\text { mothers }\end{array}$} \\
\hline Yes & 299 & 73.8 \\
\hline No & 106 & 26.2 \\
\hline \multicolumn{3}{|l|}{$\begin{array}{l}\text { Advice on danger signs during } \\
\text { pregnancy }\end{array}$} \\
\hline Yes & 235 & 58 \\
\hline No & 170 & 42 \\
\hline \multicolumn{3}{|l|}{ Maternity care } \\
\hline Respectful maternity care & 349 & 86.2 \\
\hline Disrespectful maternity care & 56 & 13.8 \\
\hline \multicolumn{3}{|l|}{$\begin{array}{l}\text { Waiting time to get ANC at health } \\
\text { facility }\end{array}$} \\
\hline$<30 \mathrm{~min}$ & 240 & 59.3 \\
\hline$\geq 30 \mathrm{~min}$ & 165 & 40.7 \\
\hline
\end{tabular}

$\mathrm{CI}=2.3-15.9)$, and $30-34$ years $(\mathrm{AOR}=3.2, \mathrm{CI}=1.14-9.2)$, advice on danger signs during pregnancy $(\mathrm{AOR}=4.53$, $95 \% \mathrm{CI}=2.7-7.52)$, respectful maternity care $(\mathrm{AOR}=8.2$, 95\% CI=3.3-20.4), two ( $\mathrm{AOR}=2.1, \mathrm{CI}=1.1-4.0)$, three $(\mathrm{AOR}=3.8, \quad \mathrm{CI}=2.0-7.52)$, and more than three ( $\mathrm{AOR}=3.3, \mathrm{CI}=1.5-7.2)$ previous $\mathrm{ANC}$ visits, and planned pregnancy $(\mathrm{AOR}=2.8, \mathrm{CI}=1.6-4.8)$ were statistically significant associated with women's satisfaction with ANC services (Table 4).

\section{Discussion}

The results of this study showed that $53.8 \%$ of women were satisfied $(95 \% \mathrm{CI}=48.7-59 \%)$ with ANC services. This finding is in line with a previous study conducted in Ethiopia. ${ }^{5}$ However, the current finding is higher than in other studies conducted in Ethiopia. ${ }^{21,22}$ On the other hand, this finding was lower than in yet other studies conducted in Ethiopia. ${ }^{19,23}$ Similarly, the result of this 
Table 4 Bivariate and Multivariable Analyses of Associated Factors of Women's Satisfaction with Antenatal Care Service Among Women Attending Antenatal Care at Public Health Facilities, Ethiopia, 2019

\begin{tabular}{|c|c|c|c|c|}
\hline \multirow[t]{2}{*}{ Variables } & \multicolumn{2}{|c|}{ Women's Satisfaction with ANC Service } & \multirow[t]{2}{*}{ Crude OR $(95 \% \mathrm{Cl})$} & \multirow[t]{2}{*}{ Adjusted OR $(95 \% \mathrm{Cl})$} \\
\hline & Satisfied & Dissatisfied & & \\
\hline \multicolumn{5}{|l|}{ Maternity care } \\
\hline Respectful maternity care & 209 & 140 & $7.8 * * *(3.7-16.4)$ & $8.2 * * *(3.3-20.4)$ \\
\hline Disrespectful maternity care & 9 & 47 & 1 & \\
\hline \multicolumn{5}{|c|}{ Had advice on danger signs in pregnancy } \\
\hline Yes & 170 & 65 & $6.65 * * *(4.3-10.3)$ & $4.53 * * *(2.7-7.52)$ \\
\hline No & 48 & 122 & 1 & \\
\hline \multicolumn{5}{|l|}{ Maternal age (years) } \\
\hline 18-24 & 38 & 50 & $2.2(0.88-5.4)$ & $4.45 * *(1.5-12.9)$ \\
\hline $25-29$ & 131 & 79 & $4.8^{* * *}(2.0-11.2)$ & $6.04 * * *(2.3-15.9)$ \\
\hline $30-34$ & 41 & 35 & $3.4^{* *}(1.34-8.5)$ & $3.2 *(1.14-9.2)$ \\
\hline$\geq 35$ & 8 & 23 & 1 & \\
\hline \multicolumn{5}{|c|}{ Number of previous ANC visits } \\
\hline 0 or 1 & 55 & 111 & 1 & \\
\hline 2 & 44 & 36 & $2.5^{* * *}(1.43-4.26)$ & $2.1 *(1.1-4.0)$ \\
\hline 3 & 72 & 24 & $6.1 * * *(3.45-10.64)$ & $3.8^{* * *}(2.0-7.52)$ \\
\hline$\geq 4$ & 47 & 16 & $5.93 * * *(3.1-11.4)$ & $3.3 * *(1.5-7.2)$ \\
\hline \multicolumn{5}{|l|}{ Characteristics of pregnancy } \\
\hline Unplanned & 89 & 139 & 1 & \\
\hline Planned & 129 & 48 & $4.2 * * *(2.7-6.4)$ & $2.8 * *(1.6-4.8)$ \\
\hline
\end{tabular}

Notes: $* p \leq 0.05, * * p \leq 0.01, * * * p \leq 0.001$.

Abbreviation: ANC, antenatal care.

study was also lower than in studies conducted in Asian countries. ${ }^{13-15}$ The discrepancy may be because the quality of ANC services differs from setting to setting and from time to time. It may also be due to satisfaction being subjective. Differences between studies are also caused by authors using different questionnaires to measure satisfaction, which give different results.

Women whose age was less than 35 years were more likely to be satisfied with ANC services than those whose age was greater than or equal to 35 years. No other studies have found this finding before. This finding could be related to there being more participants who had many children among women whose age was greater than or equal to 35 years. Because of this, unplanned pregnancy could be more common among participants who had repeated pregnancies. ${ }^{19,22}$

This study indicated that mothers who did not report disrespectful maternity care were more likely to be satisfied with ANC services than those who reported disrespectful maternity care. However, no other studies have revealed this finding. Disrespectful maternity care may traumatize women psychologically and they may have no confidence in the ANC services. Moreover, violation of women's privacy is part of disrespectful maternity care, including the examination of pregnant women without closing the door during the ANC service. ${ }^{19}$ Therefore, this activity is disrespectful maternity care and it may make the women feel ashamed. Women who had received advice on danger signs in pregnancy during ANC services were 4.53 times more likely to be satisfied with ANC services than those who were given no advice on danger signs in pregnancy during ANC services. This finding is in line with studies conducted in Kazakhstan and Ethiopia. ${ }^{14,21,24}$ This is because full information and knowledge about danger signs in pregnancy is acquired during ANC sessions of counseling, advice, and health education. Moreover, having knowledge about danger signs in pregnancy increases women's satisfaction with ANC services and ANC service utilization.

The odds of women's satisfaction with ANC services were 2.8 times higher among pregnant women whose pregnancy was planned compared to pregnant women whose pregnancy was unplanned. This finding is similar to the result from a previous study conducted in 
Ethiopia. ${ }^{19}$ The possible reason could be that women who had an unplanned pregnancy may have less interest in their pregnancy. These women may also have more experience of instability in continuing the pregnancy than women whose pregnancies were planned.

Pregnant women who had made two or more previous ANC visits were more likely to be satisfied with ANC services than women who had made no previous visits or only one previous ANC visit. ${ }^{25,26}$ This could be due to increasing awareness and knowledge of pregnant women through repeated ANC visits. Repeated ANC fulfills the clients' need and also increases the effective response for the clients' need. Those mothers who had made three, and four and above ANC contacts were 3.8 and 3.3 times more satisfied than women who were making their first ANC contact or who had one previous ANC contact. The reason for this may be that repeated ANC contact adds client satisfaction, secondary to awareness and knowledge of pregnant women about the advantages of ANC services.

\section{Study Strengths and Limitations}

The major strength of this study was the face-to-face interview technique, which contributed to the $100 \%$ response rate. The risk of bias was restricted by ensuring privacy for the interviewees. This study addresses women's satisfaction with ANC services, which is typically improved by increasing advice on danger signs in pregnancy, respectful maternity care, planned pregnancy, and repeated ANC visits.

The first limitation of this study was the possibility for social desirability bias, as the study was conducted while women were visiting health facilities to use the ANC services. There could also be a possibility of recall bias because mothers were asked to report events of associated factors that may have occurred several months ago. Moreover, the responses of the participants may have been inflated or underestimated due to individuals' particular interests. The other limitation of this study was that a qualitative study was not included to strengthen the findings of this crosssectional study.

\section{Conclusion}

About half of the participants were satisfied with the ANC services. The results of this study revealed that statistically significant factors associated with women's satisfaction with ANC services were the age of participants, respectful maternity care, advice on danger signs in pregnancy, planned pregnancy, and previous ANC visits.

\section{Data Sharing Statement}

The datasets used and/or analyzed during the current study are available from the corresponding author on reasonable request.

\section{Acknowledgments}

We are thankful to the data collectors and the pregnant women attending antenatal care in public health facilities for their willingness to participate in the study. We would like to express our deepest gratitude to Bahir Dar University for giving us financial support and South Gondar Zone Health Department for providing information about the study population.

\section{Author Contributions}

All authors made a significant contribution to the work reported, whether that is in the conception, study design, execution, acquisition of data, analysis and interpretation, or in all these areas; took part in drafting, revising or critically reviewing the article; gave final approval of the version to be published; have agreed on the journal to which the article has been submitted; and agree to be accountable for all aspects of the work.

\section{Funding}

This study was funded by Bahir Dar University. The funder is not listed in the fund Ref Registry and there is no award number/grant number. The funding body had no role in the study design and collection, analysis, and interpretation of data, or in writing the manuscript.

\section{Disclosure}

The authors declare that they have no conflicts of interest for this work.

\section{References}

1. Donabedian A. The quality of care: how can it be assessed? Jama. 1988;260(12):1743-1748.

2. Morris BJ, Jahangir AA, Sethi MK. Patient satisfaction: an emerging health policy issue. Am Acad Orthop Surg. 2013;9:29.

3. Karkee R, Lee AH, Pokharel PK. Women's perception of quality of maternity services: a longitudinal survey in Nepal. BMC Pregnancy Childbirth. 2014;14(1):45. doi:10.1186/1471-2393-14-45

4. Berhan Y, Berhan A. Antenatal care as a means of increasing birth in the health facility and reducing maternal mortality: a systematic review. Ethiop J Health Sci. 2014;12(24):93-104. doi:10.4314/ejhs. v24i0.9S

5. Ejigu T, Woldie M, Kifle Y. Quality of antenatal care services at public health facilities of Bahir-Dar special zone, Northwest Ethiopia. BMC Health Serv Res. 2013;13(1):443. doi:10.1186/1472-6963-13-443 
6. Chou D, Daelmans B, Jolivet RR, Kinney M, Say L. Ending preventable maternal and newborn mortality and stillbirths. BMJ. 2015;14 (351):h4255. doi:10.1136/bmj.h4255

7. Lincetto O, Mothebesoane-Anoh S, Gomez P, Munjanja S. Antenatal Care. Opportunities for Africa's Newborns: Practical Data, Policy and Programmatic Support for Newborn Care in Africa. 2006:55-62.

8. Alkema L, Chou D, Hogan D, et al. Global, regional, and national levels and trends in maternal mortality between 1990 and 2015, with scenario-based projections to 2030: a systematic analysis by the UN maternal mortality estimation inter-agency group. Lancet. 2016;387 (10017):462-474. doi:10.1016/S0140-6736(15)00838-7

9. World Health Organization. Indicator and Monitoring Framework for the Global Strategy for Women's, Children's and Adolescents' Health (2016-2030). Geneva: World Health Organization; 2016.

10. Srivastava A, Avan BI, Rajbangshi P, Bhattacharyya S. Determinants of women's satisfaction with maternal health care: a review of literature from developing countries. BMC Pregnancy Childbirth. 2015;15 (1):97. doi:10.1186/s12884-015-0525-0

11. Adeyinka O, Jukic AM, McGarvey ST, Muasau-Howard BT, Hawley NL, Hawley NL. Predictors of prenatal care satisfaction among pregnant women in American Samoa. BMC Pregnancy Childbirth. 2017;17(1):381. doi:10.1186/s12884-017-1563-6

12. Acharya S, Sharma S, Dulal B, Aryal K. Quality of care and client satisfaction with maternal health services in nepal: further analysis of the 2015 nepal health facility survey. DHS Furth Anal Rep. 2018;(112).

13. Pricilla RA, David KV, Siva R, Vimala TJ, Rahman SP, Sankarapandian V. Satisfaction of antenatal mothers with the care provided by nurse-midwives in an urban secondary care unit. J Family Med Prim Care. 2016;5(2):420. doi:10.4103/2249-4863.192359

14. Dauletyarova MA, Semenova YM, Kaylubaeva G, et al. Are Kazakhstani women satisfied with antenatal care? Implementing the WHO tool to assess the quality of antenatal services. Int J Environ Res Public Health. 2018;15(2):325. doi:10.3390/ijerph15020325

15. Paudel YR, Mehata S, Paudel D, et al. Women's satisfaction of maternity care in Nepal and its correlation with intended future utilization. Int J Reprod Med. 2015;8:2015.

16. Ismail NI, Essa RM. Pregnant women's satisfaction with the quality of antenatal care at maternal and child health centers in El-Beheira Governorate. therapy. 2017;14:15.
17. Odetola TD, Fakorede EO. Assessment of perinatal care satisfaction amongst mothers attending postnatal care in Ibadan, Nigeria. Ann Glob Health. 2018;84(1):36. doi:10.29024/aogh.10

18. Nwaeze IL, Enabor OO, Oluwasola TA, Aimakhu CO. Perception and satisfaction with quality of antenatal care services among pregnant women at the university college hospital, Ibadan, Nigeria. Ann Ib Postgrad Med. 2013;11(1):22-28.

19. Chemir F, Alemseged F, Workneh D. Satisfaction with focused antenatal care service and associated factors among pregnant women attending focused antenatal care at health centers in Jimma town, Jimma zone, South West Ethiopia; a facility based cross-sectional study triangulated with qualitative study. BMC Res Notes. 2014;7(1):164. doi:10.1186/1756-0500-7-164

20. Asefa A, Bekele D. Status of respectful and non-abusive care during facility-based childbirth in a hospital and health centers in Addis Ababa, Ethiopia. Reprod Health. 2015;12(1):33. doi:10.1186/ s12978-015-0024-9

21. Mekonnen N, Berheto TM, Ololo S, Tafese F. Quality of antenatal care services in Demba Gofa Woreda, Gamo Gofa Zone, Rural Ethiopia. Health Sci J. 2017;11(3). doi:10.21767/1791-809X.1000502

22. Tesfaye T, Mekonnen H, Negesa L. Maternal antenatal care service satisfaction and factors associated with rural health centers, Bursa District, Sidama Zone, Southern Ethiopia: a cross-sectional study. $J$ Womens Health Care. 2017;6(2):2167-2420.

23. Yabo AN, Gebremicheal MA, Chaka EE. Assessment of quality of antenatal care (ANC) service provision among pregnant women in Ambo town public health institution, Ambo, Ethiopia, 2013. Am J Nurs Sci. 2011;4(3):57-62. doi:10.11648/j.ajns.20150403.13

24. Berhanu S Sr, Asefa Y, Giru BW. Prevalence of postnatal care utilization and associated factors among women who gave birth and attending immunization clinic in selected government health centers in Addis Ababa, Ethiopia, 2016. prevalence. 2016;26.

25. Lakew S, Ankala A, Jemal F. Determinants of client satisfaction to skilled antenatal care services at Southwest of Ethiopia: a cross-sectional facility based survey. BMC Pregnancy Childbirth. 2018;18(1):479. doi:10.1186/s12884-018-2121-6

26. Onyeajam DJ, Xirasagar S, Khan MM, Hardin JW, Odutolu O. Antenatal care satisfaction in a developing country: a cross-sectional study from Nigeria. BMC Public Health. 2018;18 (1):368. doi:10.1186/s12889-018-5285-0

\section{Publish your work in this journal}

The International Journal of Women's Health is an international, peerreviewed open-access journal publishing original research, reports, editorials, reviews and commentaries on all aspects of women's healthcare including gynecology, obstetrics, and breast cancer. The manuscript management system is completely online and includes a very quick and fair peer-review system, which is all easy to use. Visit http://www.dovepress.com/testimonials.php to read real quotes from published authors. 